\title{
High-dose immunosuppressant alters the immunological status of New Zealand white rabbits following skin transplantation
}

\author{
PEILUN CHENG ${ }^{1}$, LIMING ZHONG ${ }^{1}$, ZESHENG JIANG $^{1}$, YAN WANG $^{1,2}$, MINGXIN PAN $^{1}$ and YI GAO $^{1,2}$ \\ ${ }^{1}$ Department of Hepatobiliary Surgery, Zhujiang Hospital, Southern Medical University; \\ ${ }^{2}$ Institute of Regenerative Medicine, Southern Medical University, Guangzhou, Guangdong 510282, P.R. China
}

Received August 6, 2014; Accepted May 1, 2015

DOI: $10.3892 /$ etm.2015.2608

\begin{abstract}
The aim of this study was to investigate the effect of an immunosuppressant on the immunological status of New Zealand white rabbits after skin grafting, and to evaluate a method for monitoring the immunological status of subjects with skin transplants. The rabbits were randomly divided into allograft rejection, autograft tolerance, nontransplant, allograft low-dose immunosuppressant and allograft high-dose immunosuppressant groups. The rabbits in the low- and high-dose immunosuppressant groups were treated with cyclosporine A intravenously $8 \mathrm{~h}$ prior to skin transplantation and once daily following transplantation at doses of 2 and $25 \mathrm{mg} / \mathrm{kg}$, respectively. At 12 days after skin transplantation, the spleens of donor (female) rabbits and recipient (male) rabbits were harvested for the preparation of single-cell suspensions. The splenocytes from recipient and donor rabbits were labeled with 0.3 or $6 \mu \mathrm{M}$ carboxy fluorescein diacetate succinimidyl ester, respectively, and a mixed cell suspension was prepared. The final preparation was intravenously injected into recipient New Zealand white rabbits. The ratio of the two fluorescently labeled cell populations in the peripheral blood was measured using flow cytometry at 1,2, 4 and $8 \mathrm{~h}$ after the injection, and the cell death rate was calculated. Histological analysis was also performed on samples collected at the time of splenectomy. The cell death rates of the allograft rejection and low-dose immunosuppressant groups reached their highest levels $8 \mathrm{~h}$ after the injection of spleen cell suspension. Allogeneic spleen cells from donor male rabbits were almost completely removed within $8 \mathrm{~h}$ of injection. The cell death rate increased slowly in the nontransplant, autograft and high-dose immunosuppressant groups without specificity. This study provides a specific method for the in vivo monitoring of the
\end{abstract}

Correspondence to: Dr Mingxin Pan, Department of Hepatobiliary Surgery, Zhujiang Hospital, Southern Medical University, 253 Gongye Middle Avenue, Guangzhou, Guangdong 510282, P.R. China E-mail:pmxwxy@sohu.com

Key words: carboxy fluorescein diacetate succinimidyl ester, flow cytometry, skin grafting, transplant rejection, immunological status immunological status of patients after skin grafting. This method can quickly and accurately detect the immunological status of recipients following the injection of a mixed splenocyte suspension, thereby indicating the strength of immune rejection by the immune systems of the recipients.

\section{Introduction}

Immunosuppressants are usually used to prevent the occurrence of acute rejection following organ transplantation (1). To reduce the adverse events associated with immunosuppressants, it is helpful to preserve the immune system of recipients, to reduce the dose of immunosuppressive drugs and/or to induce immune tolerance (2-5). In order to extend the duration of graft survival and to maximally reduce the side-effects associated with immunosuppressive agents, the doses of immunosuppressants can be optimized by monitoring the immunological status of transplant recipients and rejection. A variety of monitoring methods have been reported based on different cells and molecules involved in immune responses, including: Cell-mediated lymphotoxicity assay $(6,7)$; measurement of cytokines such as interleukin (IL)-2, IL-4, IL-10, $\gamma$-interferon, tumor necrosis factor (TNF)- $\alpha$ and soluble CD30 (8-11); measurement of donor-specific antibodies in recipients' blood $(12,13)$; measuring polyclonal $\mathrm{T}$-cell responses to nonantigen-specific stimulations $(14,15)$; monitoring regulatory T-cells (Tregs) $(16,17)$; analysis of circulating mRNA precursors for cytokines $(18,19)$; and searching for rejection-related biomarkers in blood, urine or bronchoalveolar lavage fluid using proteomic methods (18,20-22). However, these immunological detection methods each have their own advantages, disadvantages and limitations due to the complexity of immune responses. In certain cases, conflicting results are obtained (23).

Currently, the evaluation of clinical symptoms together with graft biopsy is the most commonly used method for monitoring a recipient's immunological status in clinical practice. However, biopsy is an invasive procedure that has inherent limitations. To abrogate the need for biopsy, a simple in vivo examination method was designed in the present study to monitor the immunological status of New Zealand white rabbits after skin grafting, inspired by the in vivo application of lymphocyte-mediated cytotoxicity tests. 


\section{Materials and methods}

Animals. Female and male New Zealand white rabbits weighing between 1.9 and $2.5 \mathrm{~kg}$ served as donors and recipients, respectively [certification No. SCXK (Yue)-0015]. All rabbits were purchased from the Experimental Animal Center of Southern Medical University (Guangzhou, China), and all animal experiments were conducted according to the ethical guidelines of Southern Medical University.

Establishment of the skin transplantation model. Rabbits were randomly divided into five groups, namely the allograft rejection group, autograft tolerance group, nontransplant (control) group, allograft low-dose immunosuppressant group and allograft high-dose immunosuppressant group. For rabbits in the three allograft groups, a patch of skin $(3 \times 3 \mathrm{~cm})$ was cut from the back of the donor female rabbits, and the subcutaneous tissue was trimmed cleanly with ophthalmic scissors. Next, a patch of skin $(3 \times 3 \mathrm{~cm})$ was obtained from the recipient male rabbits without removing the subcutaneous tissue. The donor skin graft was fixed onto the backs of the recipients with 5-0 noninvasive synthetic sutures. Wounds were covered with gauze and fixed with tapes. In the autograft tolerance group, a patch of skin $(3 \times 3 \mathrm{~cm})$ was grafted in situ onto the back of the male rabbits as described above.

Rabbits in the allograft low-dose immunosuppressant group were treated with $2 \mathrm{mg} / \mathrm{kg}$ cyclosporine A intravenously $8 \mathrm{~h}$ prior to transplantation and once a day following transplantation for 25 days. Rabbits in the allograft high-dose immunosuppressant group were treated with $25 \mathrm{mg} / \mathrm{kg}$ cyclosporine A intravenously $8 \mathrm{~h}$ prior to transplantation and once a day following transplantation for 25 days.

Preparation of single-cell suspensions. On day 12 after the transplantation, splenectomy was performed on all rabbits. Standard layered abdominal closure was performed and the rabbits recovered uneventfully. Fluid therapies were administered to all rabbits undergoing surgery and penicillin $(80,000 \mathrm{U} / \mathrm{kg})$ was administered intravenously following the surgery. In addition, samples from all skin grafts, including the rejected grafts, were collected at the time of surgery, stained with hematoxylin and eosin (H\&E), and examined under a microscope.

Spleens of the male and female rabbits were crushed in RPMI-1640 medium, and the cell suspension was filtered with a 400-mesh stainless steel filter. Red blood cells were lysed using erythrocyte lysis buffer (BD Biosciences, San Jose, CA, USA), and a single-cell suspension was prepared with $0.01 \mathrm{~mol} / \mathrm{l}$ phosphate-buffered saline. Cells from the recipient and donor rabbits were labeled with 0.3 and $0.6 \mu \mathrm{M}$ carboxy fluorescein diacetate succinimidyl ester (Molecular Probes, Thermo Fisher Scientific, Inc., Eugene, OR, USA), respectively, at $37^{\circ} \mathrm{C}$ for $15-20 \mathrm{~min}$. Then, $5 \%$ fetal bovine serum was added to terminate the reaction. The cells were then resuspended and washed in phosphate-buffered saline. The cells labeled with 0.3 and $6 \mu \mathrm{M}$ carboxy fluorescein diacetate succinimidyl ester were mixed in 1:1 ratio, and counted after dilution to a final concentration of $5-7 \times 10^{7}$ cells $/ 1$. The cells were examined via fluorescence microscopy, and a trypan blue exclusion test was performed to ensure the proportion of viable cells was $>95 \%$.
Subsequently on day 12 , the single-cell suspension $(20 \mathrm{ml})$ containing $1 \times 10^{9}$ cells was injected into recipient male rabbits via the auricular vein.

$H \& E$ staining. Samples of skin grafts $(0.5 \times 0.5 \mathrm{~cm})$ were obtained during the surgery, fixed with formaldehyde and embedded with paraffin wax for slicing. The 5- $\mu \mathrm{m}$ slices of skin grafts underwent $\mathrm{H} \& \mathrm{E}$ staining; conventional glass slides were fixed with $95 \%$ ethanol for at $\geq 15 \mathrm{~min}$, and then treated with water for $1 \mathrm{~min}$, hematoxylin for $10 \mathrm{~min}$, running water for $15 \mathrm{~min}$, eosin for $30 \mathrm{sec}$, $95 \%$ ethanol for $1 \mathrm{~min}$ and $100 \%$ ethanol for $2 \mathrm{~min}$. The H\&E-stained slices were then observed using an XSP-BM19A optical microscope (Shanghai Optical Instrument Factory, Shanghai, China).

Flow cytometry. Blood samples were collected via auricular vein at 1,2, 4 and $8 \mathrm{~h}$ after the infusion of the single-cell suspension. The ratio of the two types of labeled cells in $200 \mu \mathrm{l}$ of peripheral blood was determined by flow cytometry. Prior to analysis, red blood cells were lysed using erythrocyte lysis buffer at room temperature, and the sample was subsequently washed three times in phosphate-buffered saline. Since the ratio of positive cells was relatively small, 100,000 cells were measured for each sample.

Calculation of the cell death rate. The degree of rejection of allogeneic donor cells was defined as the cell death rate $(\mathrm{R})$, which was calculated using the following formula: $\mathrm{R}$ $(\%)=(1-$ number of remaining allogeneic spleen cells/number of remaining isogeneic spleen cells) x 100.

Statistical analysis. All data were analyzed using SPSS software, version 13.0 (SPSS Inc., Chicago, IL, USA). Values were presented as means \pm standard deviation. One-way analysis of variance was applied for comparing groups. The Dunnett t-test (2-sided) was used to compare the allograft rejection group to the other four groups. $\mathrm{P}<0.05$ was considered to indicate a statistically significant difference.

\section{Results}

Low-dose immunosuppressant has no significant effect on graft survival, but high-dose immunosuppressant prolongs graft survival time. To investigate the effect of different doses of immunosuppressant on graft survival, the number of days that the grafts in each group survived were determined. In the allograft rejection group, the graft turned black on day 9 after the transplantation, indicating complete skin necrosis, with a mean graft survival time of $13.0 \pm 1.0$ days. In the low-dose immunosuppressant group, rejection occurred on day 12 after the transplantation with a mean survival time of $13.4 \pm 1.1$ days, whereas the mean survival time of skin grafts in the high-dose immunosuppressant group was $23.2 \pm 1.5$ days. In the autograft group, the mean graft survival time was longer than 50 days (Fig. 1). These data indicated that low-dose immunosuppressant had no significant effect on graft survival, but high-dose immunosuppressant prolonged the survival time of the graft.

High-dose immunosuppressant is more effective than low-dose immunosuppressant in suppressing histological 


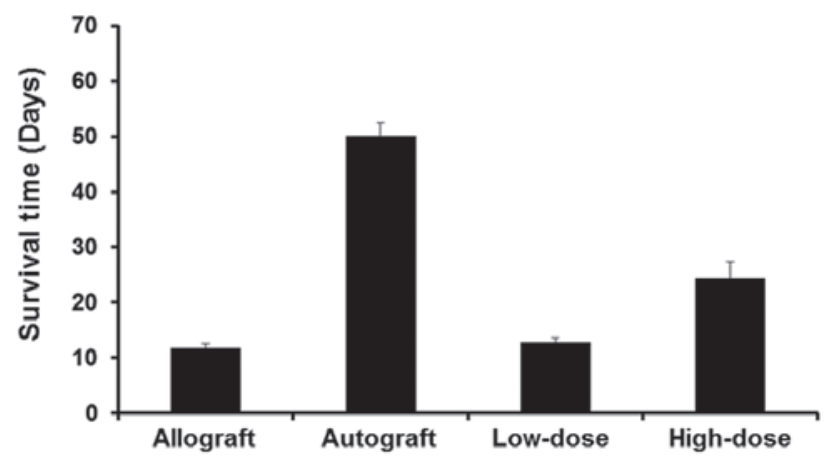

Figure 1. Survival time of skin grafts in allograft, autograft, low-dose immunosuppressant and high-dose immunosuppressant groups.

A

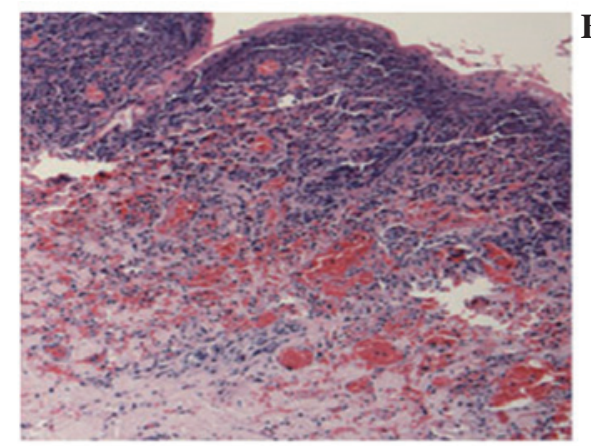

C

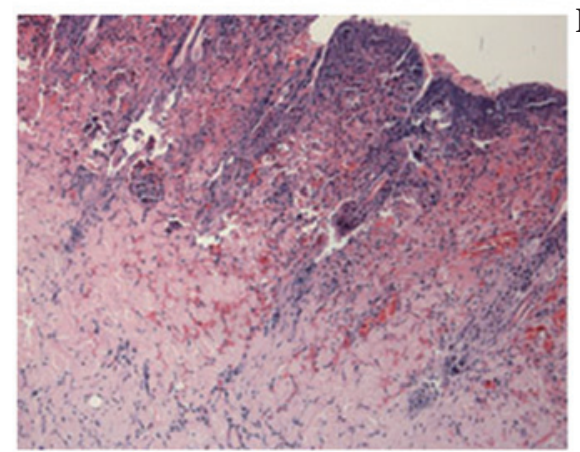

B

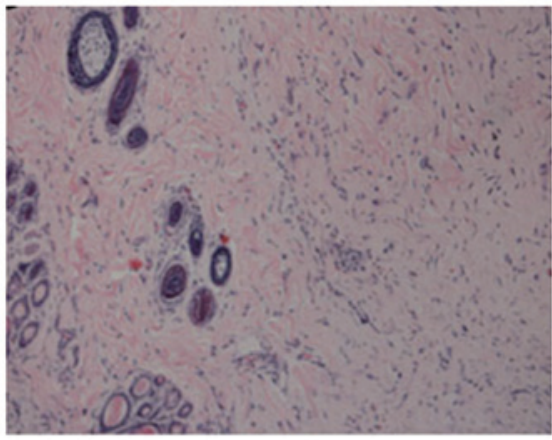

D

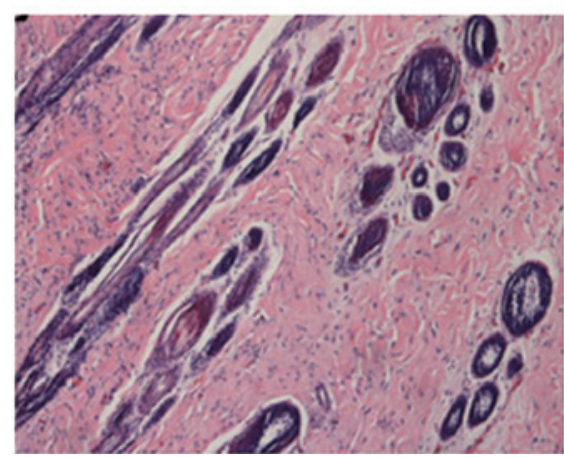

Figure 2. Histological investigation of skin grafts following transplantation for the (A) allograft rejection group, (B) autograft group, (C) low-dose immunosuppressant group and (D) high-dose immunosuppressant group. The samples were stained with hematoxylin and eosin, and examined under a microscope (magnification, x100). In (A) and (C) necrosis of the skin graft, damaged skin structures and massive lymphocytic infiltration were observed. In (B) and (D) the skin grafts survived without necrosis, and the skin structures were normal without lymphocytic infiltration.

changes of the skin grafts. To visualize the effects of different doses of immunosuppressant on the skin grafts, the tissues were stained with H\&E and observed under a microscope. In the allograft rejection group and low-dose immunosuppressant group, necrosis of the skin graft, damaged skin structure and massive lymphocytic infiltration were observed. By contrast, in the autograft and high-dose immunosuppressant groups, the skin grafts showed no histological changes that were associated with necrosis. In addition, the skin structure was normal, and no lymphocytic infiltration was observed (Fig. 2). These data showed that high-dose immunosuppressant was more effective than low-dose immunosuppressant in suppressing histological changes in the skin grafts.

Allogeneic splenic cells are specifically destroyed in the recipients, but are rescued by high-dose immunosuppressant. To test how different doses of immunosuppressant affect the ratio of allogeneic splenocytes to isogeneic splenocytes, flow cytometry was employed. In the allograft group, the ratios of the remaining allogeneic splenocytes to the isogeneic splenocytes (as ratios of percentages) at $1,2,4$ and $8 \mathrm{~h}$ after the injection were 3.9:7, 1.07:2.13, 0.35:1.12 and 0.09:0.41, with the proportion of remaining allogeneic spleen cells decreasing rapidly. In the autograft group, the ratios of the remaining allogeneic splenocytes to the isogeneic splenocytes were 2.44:2.44, 1.50:1.64, 1.23:1.46 and $0.93: 1.31$, which were similar to the ratios in the nontransplant group (3.67:3.45, 2.75:3.12, 1.92:2.45 and 1.21:1.72). In the low-dose immunosuppressant group, the results were similar to those in the allograft group (1.65:4.52, 0.81:3.02, 0.28:1.39 and $0.11: 1.07)$. Finally, the ratios of remaining allogeneic spleen cells to isogeneic spleen cells in the high-dose immunosuppressant group were 8.75:9.21, 2.65:2.86, 1.45:1.67, and 0.93:1.20, which were similar to those in the autograft and control groups (Fig. 3). In addition, statistical analysis showed that the cell death rate 
A

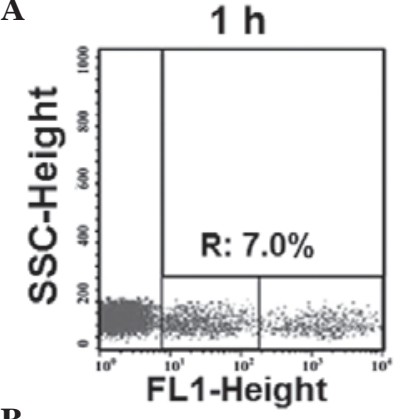

B

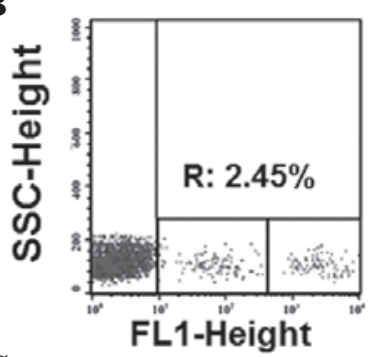

C

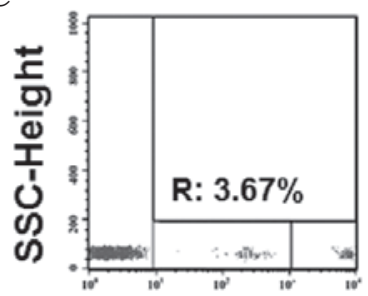

D

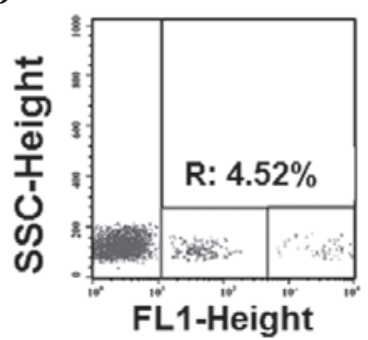

$\mathbf{E}$

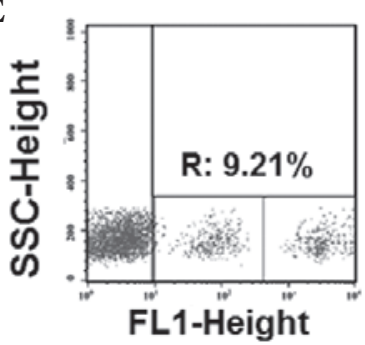

$2 \mathrm{~h}$
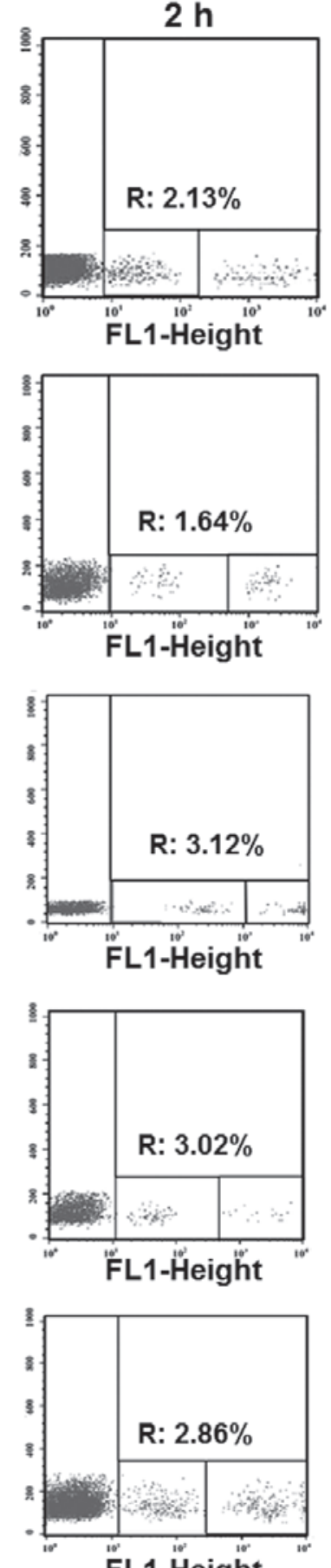

$4 \mathrm{~h}$

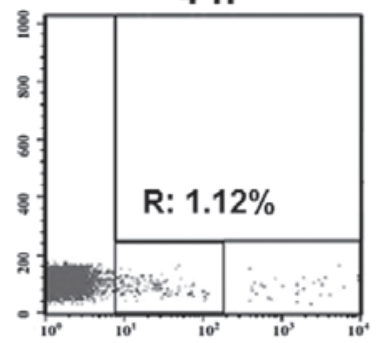

FL1-Height
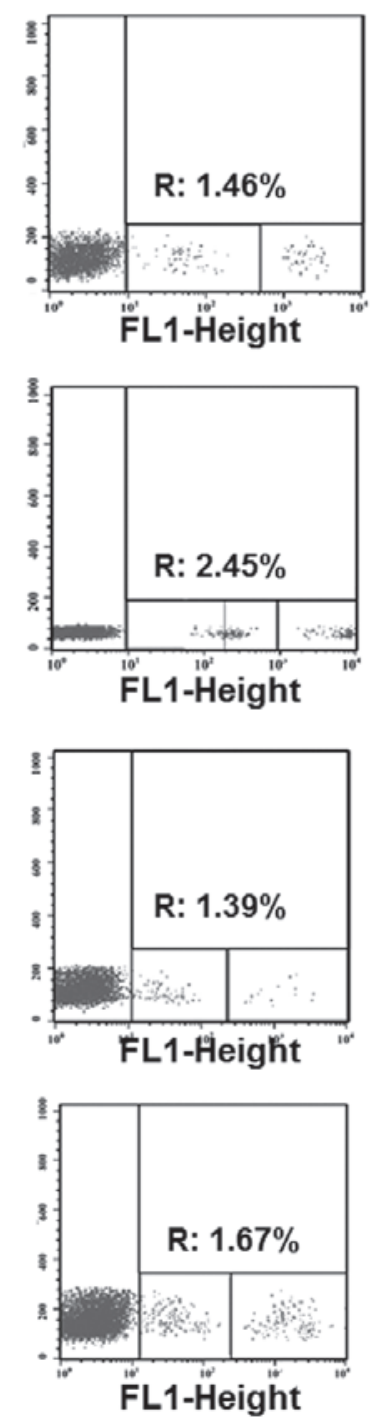

$8 \mathrm{~h}$

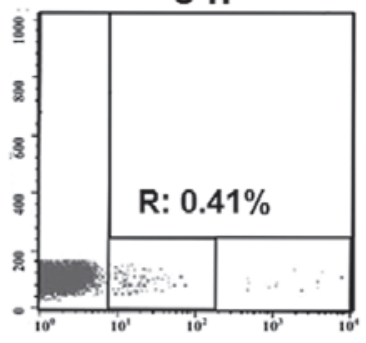

FL1-Height
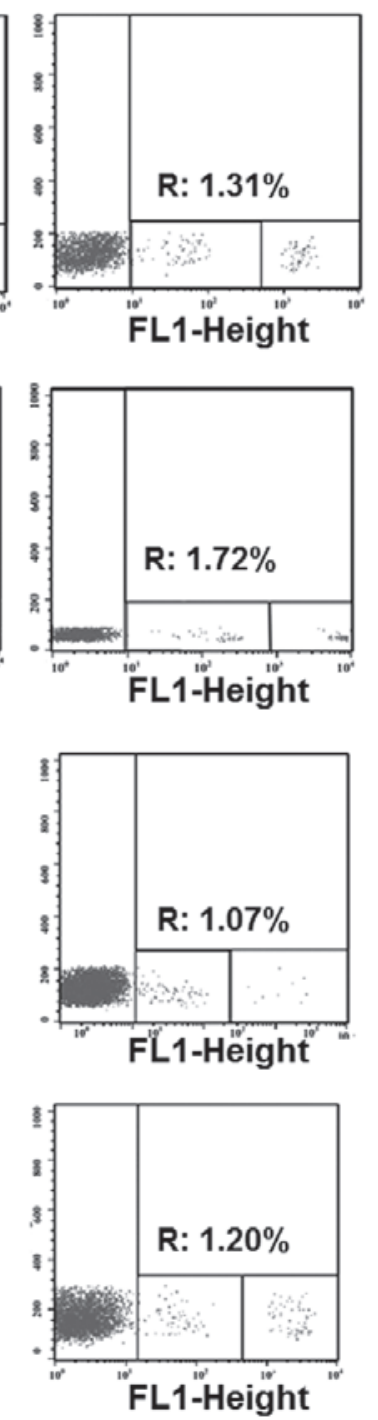

Figure 3. Ratio of remaining allogeneic splenocytes to isogeneic splenocytes in the (A) allograft, (B) autograft, (C) control, (D) low-dose immunosuppressant and (E) high-dose immunosuppressant groups at 1,2, 4 and $8 \mathrm{~h}$ after injection. Blood samples were collected via the auricular vein at 1, 2, 4 and $8 \mathrm{~h}$ after the infusion of a single-cell suspension of labeled splenocytes. The ratio of the two types of labeled cells in $200 \mu 1$ peripheral blood was determined by flow cytometry. For each sample, 100,000 cells were measured. R, cell death rate; SSC, side scatter; FL1, fluorescence intensity in X-axis.

of the allograft group was significantly different from those of all other groups with the exception of the low-dose immunosuppressant group at 1, 2, 4 and $8 \mathrm{~h}$ after injection $(\mathrm{P}<0.05)$, and no significant differences were observed between the cell death rates of the allograft and low-dose immunosuppressants group at 1,2, 4 and $8 \mathrm{~h}$ after injection ( $\mathrm{P}>0.05$; Fig. 4). These data suggest that the allogeneic splenic cells were specifically destroyed in the recipients, but were rescued by treatment with a high dose of immunosuppressant.

\section{Discussion}

The current study investigated a novel and simple in vivo method to monitor the immunological status of skin graft recipients using New Zealand white rabbits. Donor splenocytes in the allograft rejection group and low-dose immunosuppressant group were specifically destroyed by graft recipients. However, specific loss of the labeled splenocytes was not evident in the autograft, nontransplant or high-dose immunosuppressant 


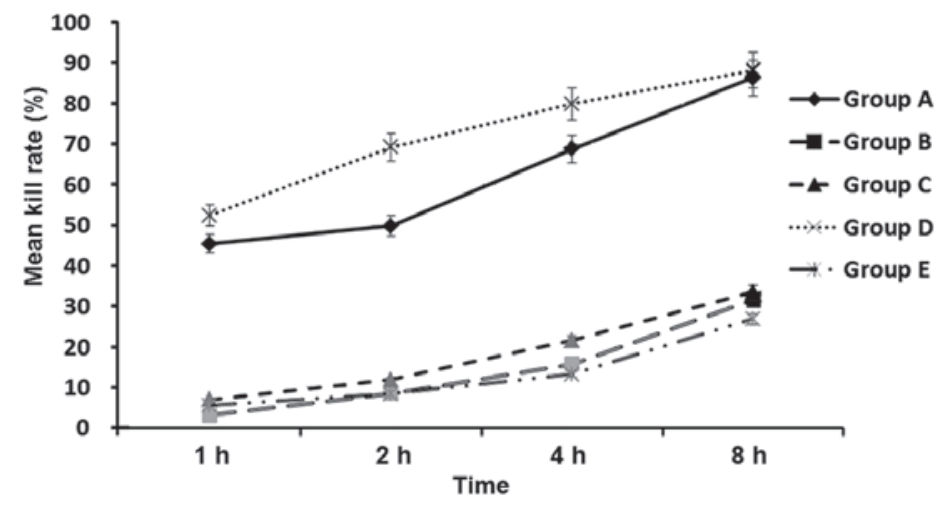

Figure 4. Cell death (kill) rates of splenocytes in the allograft (Group A), autograft (Group B), control (Group C), low-dose immunosuppressant (Group D) and high-dose immunosuppressant (Group E) groups following the transplantation. The cell death rate (R) was calculated using the following formula: $\mathrm{R}(\%)=(1$ - number of remaining allogeneic spleen cells/number of remaining isogeneic spleen cells $) \mathrm{x} 100$.

groups. Since skin transplantation induced strong rejection in the rabbits of the allograft rejection group, the bodies maintained numerous immune cells such as lymphocytes, natural killer (NK) cells, antibodies and complements. When donor cells contacted the sensitized recipient for a second time following injection of the labeled splenocytes, cell-mediated immunity (involving lymphocytes, NK cells, antibodies and complements) together with the humoral immune responses, resulted in violent attacks on donor splenic cells and severe rejection. As a result, the splenocytes were rejected and almost completely removed by the rabbits within $8 \mathrm{~h}$ following injection of the labeled splenocytes. The cell death rate within $8 \mathrm{~h}$ was as high as $86.19 \pm 6.95 \%$.

No specific destructive activity against the labeled splenocytes occurred in the autograft and nontransplant groups, with only gradual rejection being observed. In these groups, the cell death rates were $31.58 \pm 3.41$ and $33.51 \pm 3.49 \%$ at $8 \mathrm{~h}$, respectively. This was because the immune systems were not 'activated' in the two groups, and the recipients were not in a state of sensitization, that is, no sensitized lymphocytes, antibodies, and complements were present.

Similarly, in the low-dose immunosuppressant group, the dosage of immunosuppressive agent was not sufficient to effectively inhibit rejection of donor skin and splenocytes by the recipient, resulting in the preservation of a large number of sensitized immune mediators such as lymphocytes, complements and antibodies. The cell death rate at $8 \mathrm{~h}$ was $88.14 \pm 4.21 \%$, with no statistically significant difference from that of the allograft rejection group. By contrast, the recipients' immune systems were inhibited in the high-dose immunosuppressant group, with a cell death rate of $26.82 \pm 3.26 \%$ at $8 \mathrm{~h}$, which was significantly different from that in the allograft rejection group, but similar to those of the nontransplant and autograft groups $(P>0.05)$. Therefore, the current study accurately reflected the immunological status of the recipients following transplantation, and was able to clearly distinguish between immune rejection and immune tolerance following transplantation.

Fluorescence-based flow cytometry is advantageous for use as a functional assay for specific cytotoxic T lymphocytes (CTLs) $(24,25)$, as it improves on the sensitivity and specificity of in vitro CTL techniques. Fluorescence-based flow cytometry is safe for use in clinical and laboratory experiments and avoids radioactive contamination during experimentation. Unfortunately, it is not able to simulate the biological environment of the body during in vitro CTL experiments due to numerous factors. Therefore, some researchers have suggested using in vivo CTL experiments (26-28), in which isogeneic target cells and antigen peptides are injected into animal bodies to compare the in vivo CTL activity of these 'treated' animals with that of the controls. However, these experiments are limited by the detection of reactions between specific CTLs and simple antigens. Antigens for immune rejection are complex antigens, including major histocompatibility antigen (MHC), minor histocompatibility antigen $(\mathrm{mH})$ and other antigens that are involved in the rejection, such as $\mathrm{ABO}$ blood group antigens and tissue-specific antigens. Therefore, transplantation rejection is a complicated process involving both cell-mediated immunity and humoral immunity against complex antigens. In vivo experiments of lymphocyte toxicity reflect only the in vivo destructive effect of CTL on certain specific antigens, but cannot comprehensively reflect the rejection process.

The present study was inspired by the application of an in vivo cytotoxicity test. Donor cell complex antigens injected into the recipient not only reflect in vivo CTL activity but also the effect of complicated cellular and humoral immunity on in vivo transplantation rejection. As the splenocytes were from donor rabbits, their antigenicity was nearly the same as the that of the skin graft. Moreover, the number of dead donor cells indirectly reflected the degree of transplantation rejection, since the experiment was conducted in vivo. This assay reflects the rejection and destructive activity of CTLs, as well as a series of destructive effects on cellular and humoral immunity mediated by a variety of immune molecules. Therefore, this assay comprehensively monitors the immunological status of the recipients. The detection method described herein proved to be antigen-specific, and this technique appears to be an excellent method of monitoring the immunological status of a recipient following transplantation.

This in vivo experiment has the potential for wider application. If a sufficient number of target cells and isogeneic internal control cells can be obtained, the fluorescent dye can stain all living cells in the animals (29). 
In summary, the present study investigated an experimental protocol that can accurately reflect the immunological status of transplantation recipients and the intensity of transplantation rejection. The method used in this study has previously been demonstrated to be feasible in mouse skin transplantation (30). However, the protocol is invasive, as it requires a splenectomy in order to create a single-cell suspension. Thus, the application of this method remains relatively limited and further studies are required.

\section{Acknowledgements}

This study was partly supported by the National Natural Science Foundation of China (no.30972825).

\section{References}

1. Segoloni GP: New immunodepressant drugs for the prevention and control of kidney transplant rejection. G Ital Nefrol 22: 3-15, 2005 (In Italian).

2. Cobbold SP, Adams E, Graca L, Daley S, Yates S, Paterson A, et al: Immune privilege induced by regulatory $\mathrm{T}$ cells in transplantation tolerance. Immunol Rev 213: 239-255, 2006.

3. Pretagostini R, Cinti P, Lai Q, Poli L and Berloco PB: Minimization of immunosuppressive therapy and immunological monitoring of kidney transplant recipients with long-term allograft survival. Transpl Immunol 20: 3-5, 2008.

4. Quatra F, Lowenberg DW, Buncke HJ, Romeo OM, Brooks D, Buntic RF and Baxter-Lowe LA: Induction of tolerance to composite tissue allograft in a rat model. Microsurgery 26 573-578, 2006

5. Tryphonopoulos P, Ruiz P, Weppler D, Nishida S, Levi DM, Moon J, Tekin A,Velez M, Neuman DR, Island E, Selvaggi and Tzakis AG: Long-term follow-up of 23 operational tolerant liver transplant recipients. Transplantation 90: 1556-1561, 2010.

6. Ashokkumar C, Talukdar A, Sun Q, Higgs BW, Janosky J, Wilson P, Mazariegos G, Jaffe R, Demetris A, Dobberstein J, Soltys K, Bond G, Thomson AW, Zeevi A and Sindhi R: Allospecific $\mathrm{CD} 154^{+} \mathrm{T}$ cells associate with rejection risk after pediatric liver transplantation. Am J Transplant 9: 179-191, 2009.

7. Weimar W, Rischen-Vos J, de Kuiper P, Gregoor PJ, IJzermans N, van Besouw NM, et al: Tapering immunosuppression in recipients of living donor kidney transplants. Nephrol Dial Transplant 19 (Suppl 4): iv61-iv63, 2004.

8. Amirzargar A, Lessanpezeshki M, Fathi A, Amirzargar M, Khosravi F, Ansaripour B and Nikbin B: TH1/TH2 cytokine analysis in Iranian renal transplant recipients. Transplant Proc 37: 2985-2987, 2005.

9. Sengul S, Keven K, Gormez U, Kutlay S, Erturk S and Erbay B: Identification of patients at risk of acute rejection by pretransplantation and posttransplantation monitoring of soluble CD30 levels in kidney transplantation. Transplantation 81: 1216-1219, 2006.

10. Cinti P, Pretagostini R, Arpino A, Tamburro ML, Mengasini S, Lattanzi R, et al: Evaluation of pretransplant immunologic status in kidney-transplant recipients by panel reactive antibody and soluble CD30 determinations. Transplantation 79: 1154-1156, 2005.

11. Süsal C, Döhler B, Sadeghi M, Salmela KT, Weimer R, Zeier M and Opelz G: Posttransplant sCD30 as a predictor of kidney graft outcome. Transplantation 91: 1364-1369, 2011.

12. Gebel HM, Bray RA and Nickerson P: Pre-transplant assessment of donor-reactive, HLA-specific antibodies in renal transplantation: Contraindication vs. risk. Am J Transplant 3: 1488-1500, 2003.

13. Worthington JE, Martin S, Al-Husseini DM, Dyer PA and Johnson RW: Posttransplantation production of donor HLA-specific antibodies as a predictor of renal transplant outcome. Transplantation 75: 1034-1040, 2003.
14. Israeli M,Klein T, Sredni B, Avitzur Y, Mor E, Bar-Nathen N, et al: A new parameter in immune monitoring of pediatric liver transplantation recipients. Liver Transpl 14: 893-898, 2008.

15. Kowalski RJ, Post DR, Mannon RB, Sebastian A, Wright HI, Sigle G, Burdick J, Elmagd KA, Zeevi A, Lopez-Cepero M, Daller JA, Gritsch HA, Reed EF, Jonsson J, Hawkins D and Britz JA: Assessing relative risks of infection and rejection: A meta-analysis using an immune function assay. Transplantation 82: 663-668, 2006.

16. Li Y, Koshiba T, Yoshizawa A, Yonekawa Y, Masuda K, Ito A, Ueda M, Mori T, Kawamoto H, Tanaka Y, Sakaguchi S, Minato N, Wood KJ and Tanaka K: Analyses of peripheral blood mononuclear cells in operational tolerance after pediatric living donor liver transplantation. Am J Transplant 4: 2118-2125, 2004.

17. Cortesini R, Renna-Molajoni E, Cinti P, Pretagostini R, Ho E, Rossi P and Suciu-Foca Cortesini N: Tailoring of immunosuppression in renal and liver allograft recipients displaying donor specific T-suppressor cells. Hum Immunol 63: 1010-1018, 2002.

18. Wolf T, Oumeraci T, Gottlieb J, Pich A, Brors B, Eils R, Haverich A, Schlegelberger B, Welte T, Zapatka M and von Neuhoff N: Proteomic bronchiolitis obliterans syndrome risk monitoring in lung transplant recipients. Transplantation 92: 477-485, 2011.

19. Cookson S, Doherty DG, Todryk S, Gibbs P, Portmann B, O'Grady J, et al: Hepatic expression of IL-15 mRNA is associated with liver graft acceptance. Transpl Immunol 11: 39-48, 2003.

20. Schaub S, Rush D, Wilkins J, Gibson IW, Weiler T, Sangster K, et al: Proteomic-based detection of urine proteins associated with acute renal allograft rejection. J Am Soc Nephrol 15: 219-227, 2004.

21. El Essawy B, Otu HH, Choy B, Zheng XX, Libermann TA and Strom TB: Proteomic analysis of the allograft response. Transplantation 82: 267-274, 2006.

22. Sigdel TK and Sarwal MM: The proteogenomic path towards biomarker discovery. Pediatr Transplant 12: 737-747, 2008.

23. Truong DQ, Bourdeaux C, Wieërs G, Saussoy P, Latinne D and Reding R: The immunological monitoring of kidney and liver transplants in adult and pediatric recipients. Transpl Immunol 22: 18-27, 2009.

24. Rodrigo E, López-Hoyos M, Corral M, Fábrega E, Fernández-Fresnedo G, San Segundo D, et al: ImmuKnow as a diagnostic tool for predicting infection and acute rejection in adult liver transplant recipients: A systematic review and meta-analysis. Liver Transpl 18: 1245-1253, 2012.

25. Li B, Tian L, Diao Y, Li X, Zhao L and Wang X: Exogenous IL-10 induces corneal transplantation immune tolerance by a mechanism associated with the altered Th1/Th2 cytokine ratio and the increased expression of TGF- $\beta$. Mol Med Rep 9: 2245-2250, 2014

26. Hermans IF, Silk JD, Yang J, Palmowski MJ, Gileadi U, McCarthy $\mathrm{C}$, et al: The VITAL assay: A versatile fluorometric technique for assessing CTL- and NKT-mediated cytotoxicity against multiple targets in vitro and in vivo. J Immunol Methods 285: 25-40, 2004.

27. Ritchie DS, Hermans IF, Lumsden JM, Scanga CB, Roberts JM, Yang J, et al: Dendritic cell elimination as an assay of cytotoxic T lymphocyte activity in vivo. J Immunol Methods 246: 109-117, 2000.

28. Weist BM, Hernandez JB and Walsh CM: Loss of DRAK2 signaling enhances allogeneic transplant survival by limiting effector and memory $\mathrm{T}$ cell responses. Am J Transplant 12: 2220-2227, 2012.

29. Barchet W, Oehen S, Klenerman P, Wodarz D, Bocharov G, Lloyd AL, et al: Direct quantitation of rapid elimination of viral antigen-positive lymphocytes by antiviral CD8(+) T cells in vivo. Eur J Immunol 30: 1356-1363, 2000.

30. Jiang Z, Gao Y, Pan M and Zhong L: Reagent for monitoring immune state of rabit after skin grafting, and preparation method thereof. Chinese Patent CN201210013937. Filed, January 17, 2012; Issued July 18, 2012. 